\title{
Inovasi Financial Technology (Fintech) Pada Asuransi Syariah (Studi Kasus: PT Duta Danadyakasa Teknologi)
}

\author{
Indri Nuranggraeni ${ }^{1}$ \\ Universitas Ibn Khaldun, Jl. K.H Sholeh Iskandar Km 2 Bogor \\ Email: indrinuranggraeni9999@gmail.com
}

\begin{abstract}
This study aims to identify problems, solutions and strategies in decision making of fintech innovation insurance, with the approach method is Analytic Network Process (ANP). The data collections which are depth interview and questionnaire were collected from the respondent. The results showed that the priority issues faced in fintech innovation insurance are human aspect which consists of human resource lacks and regulatory challenges; product aspect which consists of product penetration and asset market penetration fractional shari'ah. Solutions which are needed in fintech innovation insurance are aspect human which consists of resource and regulation minimalism; product aspect which consists of product research and product innovation. Strategies in fintech innovation insurance are socialization, education, cooperation and digital marketing. Socialization gives the most influence on fintech innovation insurance to introduce fintech in facing digital era. Education needs to be held periodically as well as in the process of fintech to get the assistance of the Otoritas Jasa Keuangan (OJK) as a regulatory to comply with the government policy. It needs the cooperation among companies from being charged business model with the existence of promos for insurance participants or potential participants so that people recognize and be interested, invite to all society levels of the insurance importance in life to reduce any risk that might occur and to invite all people participating in fintech innovation.
\end{abstract}

Keywords: Analytic Network Process, islamic insurance, fintech

\begin{abstract}
Abstrak
Penelitian ini bertujuan untuk mengidentifikasi masalah, solusi dan strategi dalam pengambilan keputusan dalam inovasi fintech asuransi, dengan pendekatan metode Analytic Network Process (ANP). Pengumpulan data yang dilakukan melalui wawancara mendalam (indepth interview) dan pengisian kuesioner oleh responden. Hasil penelitian ini menunjukkan bahwa masalah prioritas yang dihadapi dalam inovasi fintech asuransi diantaranya aspek human yang terdiri dari kurangnya SDM dan tantangan regulasi, aspek produk terdiri dari penetrasi produk dan asset market penetration asuransi syariah kecil. Solusi yang diperlukan dalam inovasi fintech asuransi diantarnya aspek human yang terdiri dari minimalisir SDM dan regulasi, aspek produk terdiri dari riset produk dan inovasi produk. Strategi dalam inovasi fintech asuransi terdiri dari sosialisasi, edukasi, kerjasama dan digital marketing. Sosilisasi memiliki pengaruh paling besar terhadap inovasi fintech asuransi untuk memperkenalkan fintech dalam menghadapi era digital. Edukasi berkala perlu diadakan serta dalam prosesnya fintech tersebut mendapatkan pendampingan dari Otoritas Jasa Keuangan (OJK) sebagai regulator agar sesuai dengan kebijakan pemerintah. Perlu adanya kerjasama antar perusahaan agar tidak dibebankan bisnis modelnya dengan adanya promo-promo kepada peserta atau calon peserta agar orang mengenal dan tertarik, mengajak kepada masyarkat pentingnya asuransi dalam kehidupan untuk mengurangi segala resiko yang mungkin akan terjadi dan mengajak semua kalangan untuk berpartisipasi dalam inovasi fintech asuransi.
\end{abstract}

Kata Kunci: Analytic Network Process, Asuransi Syariah, Fintech

1 Nomor telepon: 089636646848 


\section{PENDAHULUAN}

\section{Latar Belakang}

Perusahaan asuransi merupakan perusahaan non bank yang mempunyai peranan yang tidak jauh berbeda seperti bank yaitu bergerak dalam bidang layanan jasa yang diberikan kepada masyarakat dalam mengatasi resiko yang akan terjadi dimasa yang akan datang (Chrismastianto,2017).

Pada hakikatnya, secara teoritis semangat yang terkandung dalam sebuah lembaga asuransi tidak bisa dilepaskan dari semangat sosial dan saling tolong menolong (Ali, 2003). Sebagai manusia biasa tidak seorang pun yang mengetahui resiko apa yang akan terjadi dimasa yang akan datang, baik kematian, sakit dan sebagainya. Dalam bisnis juga tidak menutup kemungkinan akan terjadi resiko seperti kebakaran, kerusakan atau sebagainya. Setiap resiko yang akan dihadapi harus ditanggulangi sehingga tidak menimbulkan kerugian yang lebih besar lagi, maka diperlukan perusahaan yang dapat menanggung resiko, yakni perusahaan asuransi. Upaya dan menghindari resikonya dilakukan dengan cara melimpahkannya kepada pihak lain, dan pilihan yang tepat pada institusi yakni asuransi (Leliya, 2012).

Tingkat kesadaran masyarakat Indonesia dalam berasuransi masih tergolong sangat rendah jika dibandingkan dengan kesadaran berasuransi di Negara lain.Penilaian ini terutama jika dilihat dari sudut pandang tingkat penetrasi industri untuk pasar nasional nasabah individual.Hal tersebut menyebabkan perkembangan industri asuransi di Indonesia, khususnya asuransi syariah belum signifikan. Padahal potensi pasar industri asuransi syariah untuk berkembang di Indonesia sangat besar, mengingat mayoritas $80 \%$ penduduk di Indonesia beragama Islam (Leliya, 2012).

OJK (Otoritas Jasa Keuangan) menyebutkan per 2017 bahwa indeks literasi (kesadaran masyarakat) asuransi di Indonesia baru mencapai 15,8 persen dan tingkat utilitas (tingkat kepuasan) sebesar 12,1 persen (Rusydiana, 2018). Dapat disimpulkan bahwa dari 100 orang Indonesia, baru 15-16 orang yang memahami lembaga jasa keuangan asuransi dan hanya sekitar 12 orang yang sudah menggunakan produk asuransi.
Dunia terus mengalami perubahan sesuai dengan perkembangan zaman. Negara maju maupun berkembang terus menunjukkan perubahan dan perkembangannya, seperti halnya di Indonesia. Perkembangan tersebut dapat dilihat dari segi teknologi, pembangunan maupun industri.

Perkembangan ilmu pengetahuan dan teknologi yang semakin pesat di era digital saat ini telah memengaruhi pola perilaku manusia dalam mengakses beragam informasi dan berbagai fitur layanan elektronik (Sari, 2015).

Rusydiana (2018). dalam pengembangan industri finansial teknologi keuangan syariah di Indonesia masih bermasalah, yakni kurangnya instrument kebijakan yang menjaga proses kerja fintech dan ketersedian sumber daya manusia. Berdasarkan hal tersebut perlunya kemampuan untuk mengelola dan menganalisis data di era big data, sumber daya manusia dalam pemasaran digital, kerjasama antara pemerintah (regulator), lembaga pendidikan, dan industri (lembaga keuangan).

Fintech tidak hadir sebagai pesaing dari perbankan atau lembaga keuangan lain. Keduanya dapat saling bersinergi dengan membentuk kolaborasi nyata. Sebagaimana yang disebutkan oleh Asosiasi Financial Technology Indonesia (AFI) yang menyatakan bahwa sebanyak 63,9 persen pelaku usaha fintech telah terkoneksi dengan bank melalui Application Programming Interface. Dengan begitu, fintech hadir sebagai peluang kolaborasi bagi bank dan bukan merupakan ancaman (Irfan, 2018).

Kebutuhan masyarakatakan perlindungan risiko atas terjadinya kerugian mulai menjadi hal yang diperhatikan dan menjadi kebutuhan masyarakat Indonesia. Hal tersebut ditandai dengan makin banyaknya perusahaan asuransi yang berkembang di Indonesia. Dalam memperluas jangkauannya, perusahaan asuransi melakukan pengembangan dan inovasi terkait penjualan produknya dengan menyertakan platform digital sebagai salah satu fokus utamanya (Napitupulu, Rubini, dkk. 2017).

Yusandani (2018) menyatakan bahwa permasalahan asuransi digital atau fintech asuransi adalah prosedur perjanjian secara digital, pelakasanaan perjanjian asuransi secara 
digital dan akibat hukum yang ditimbulkan apabila terjadi wanprestasi terhadap perjanjian asuransi yang dibuat secara digital.

Dengan adanya asuransi berbasis teknologi berharap inovasi ini dapat mengubah cara pandang masyarakat pada asuransi dan memberi pengalaman yang berbeda pada pengguna asuransi digital khususnya bagi kaum milenial. Perubahan ke arah digital juga merambah sampai kepada urusan kesehatan bahkan mudik, mengingat benefit penggunaan aplikasi Mobile membuat semuanya serba digital, hingga klaim pun serba digital. Pemilihan aplikasi dirasa tepat karena saat ini masyarakat khususnya kaum milenial tidak bisa lepas dari ponsel sehingga penggunaan aplikasi pun dirasa lebih mudah (Fintech, 2019).

\section{METODE PENELITIAN}

\section{Tempat dan Waktu Penelitian}

Penelitian ini dilakukan pada beberapa pakar dan praktisi dibeberapa institusi atau organisasi yang mempraktikkan fintech pada asuransi, yakni perusahaan PT Duta Danadyakasa Teknologi, Jakarta dan PT Asuransi Syariah Keluarga Indonesia (ASyKi), Bogor. Responden penelitian ini adalah pakar dan praktisi yang memiliki pemahaman mendalam mengenai fintech asuransi. Penelitian ini dilakukan pada bulan Juli hingga Oktober 2019.

\section{Jenis dan Sumber Data}

Data yang digunakan dalam penelitian ini adalah berupa data primer yang diperoleh melalui wawancara mendalam (indepth interview)mengenai masalah fintech asuransi kepada para pakar dan praktisi yang memiliki pemahaman mendalam. Penelitian dilanjutkan dengan pengisian kuesioner kepada responden pada pertemuan selanjutnya.

\section{Metode Analisis dan Pengolahan Data}

Penelitian ini merupakan jenis penelitian analisis kualitatif-kuantitatif yang bertujuan untuk menangkap suatu nilai atau pandangan yang dikuasai oleh para regulator, akademisi dan praktisi tentang fintech asuransi syariah (Juang, 2014). Alat analisis yang digunakan adalah metode Analytic Network Process
(ANP) dengan menggunakan software "Super Decisions".

ANP (Analytic Network Process) merupakan teori matematis yang mampu menganalisa pengaruh dengan pendekatan asumsi-asumsi untuk menyelesaikan bentuk permasalahan. Metode ini digunakan dalam bentuk penyelesaian dengan pertimbangan atau penyesuaian kompleksitas masalah secara penguraian sintesis disertai adanya skala prioritas yang menghasilkan pengaruh prioritas terbesar. ANP juga mampu menjelaskan model faktor-faktor dependence serta feedback nya secara sistematik. Pengambilan keputusan dalam aplikasi ANP yaitu dengan melakukan pertimbangan dan validasi atas pengalaman empirical (Rusydiana dan Devi, 2013).

ANP memiliki empat aksioma yang menjadi landasan teori, antara lain (Saaty dan Vargas, 2006):

Resiprokal: aksioma ini menyatakan bahwa jika PC (EA,EB) adalah nilai pembanding pasangan dari elemen $\mathrm{A}$ dan $\mathrm{B}$, dilihat dari elemen induknya $C$, yang menunjukkan berapa kali lebih banyak elemen A memiliki apa yang dimiliki elemen $\mathrm{B}$, maka PC $(\mathrm{EB}, \mathrm{EA})=1 / \mathrm{Pc}$ (EA. EB).

Homogenitas: menyatakan bahwa elemen-elemen yang dibandingkan dalam struktur kerangka ANP sebaiknya tidak memiliki perbedaan terlalu besar, yang dapat menyebabkan lebih besarnya kesalahan dalam menentukan penilaian elemen pendukung yang mempengaruhi keputusan.

Prioritas: pembobotan secara absolut dengan menggunakan skala interval [0.1] dan sebagai ukuran dominasi relatif.

Tabel 1. Skala Penilaian dan Numerik

\begin{tabular}{lc}
\hline \multicolumn{1}{c}{ Deskripsi } & Tingkat \\
\hline Amat sangat lebih pengaruhnya & 9 \\
Sangat lebih besar pengaruhnya & 8 \\
& 7 \\
Lebih besar pengaruhnya & 6 \\
Sedikit lebih besar pengaruhnya & 5 \\
Diantara 1-3 & 4 \\
Sama besar pengaruhnya & 3 \\
\hline
\end{tabular}

Sumber: Tanjung dan Devi (2013) 
Dependence condition: diasumsikan bahwa susunan dapat bahwa susunan dapat dikomposisikan ke dalam komponenkomponen yang membentuk bagian berupa cluster.

\section{Tahapan Penelitian}

Tahapan pada metode ANP, seperti yang dapat dilihat pada Gambar 2.

Tabel 2. Tahapan Penelitian

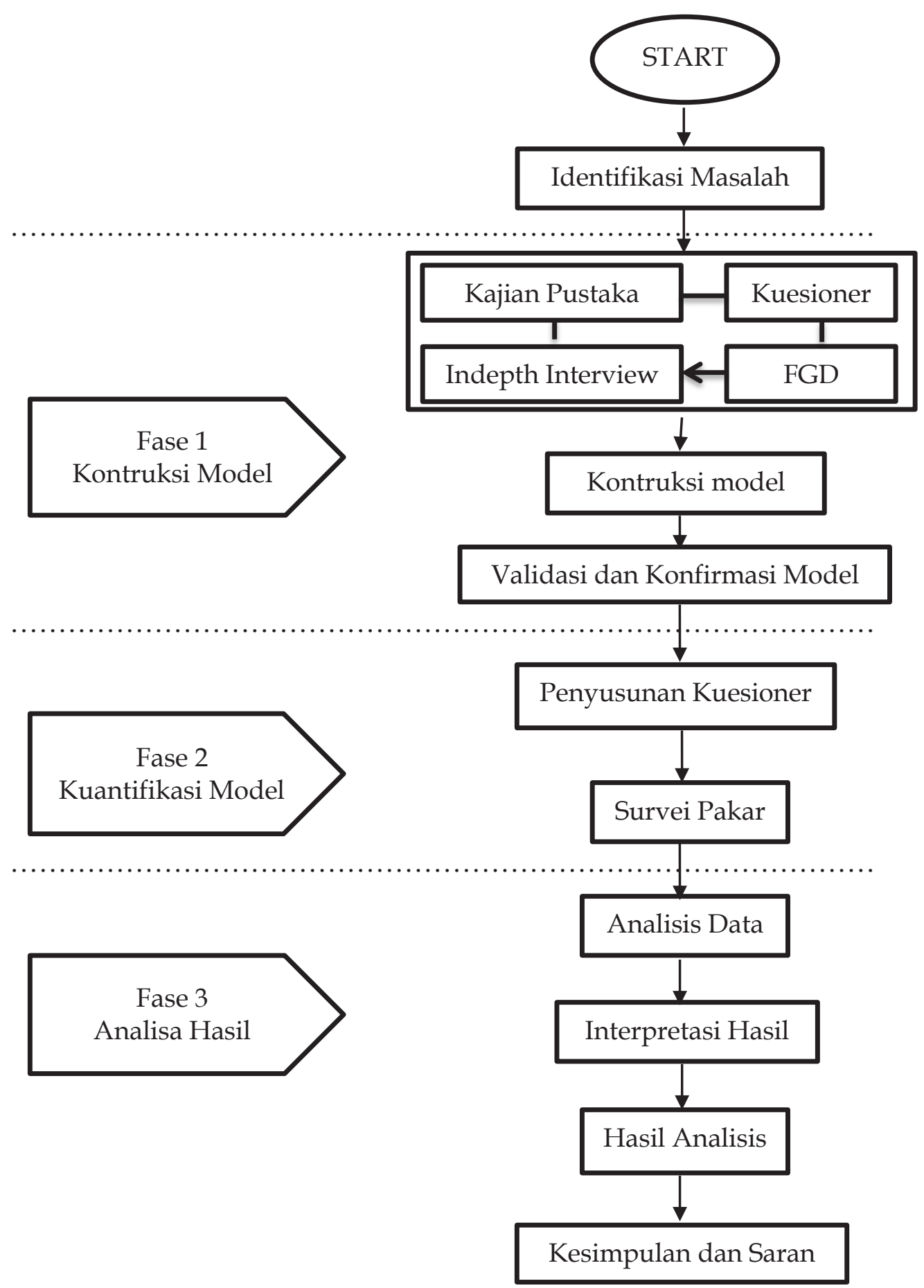

Sumber: Tanjung E Devi (2013) sumber diolah 


\section{Sintesis dan Analisis \\ Rater Agreement.}

Rater Agreement adalah ukuran yang menunjukkan tingkat kesesuaian para responden $\left(R_{1}-R_{m}\right)$ terhadap suatu masalah dalam cluster. Alat yang digunakan untuk mengukur Rater Agreement adalah Kendall's Coefficient of Concordance $(\mathrm{W} ; 0<\mathrm{W}<1)$. Jika diperoleh nilai kesesuaian adalah $1(\mathrm{~W}=1)$ maka terjadi kesepakatan sempurna antar responden. Ketika nilai $\mathrm{W}$ adalah 0 atau mendekati 0 maka, terjadi ketidakpastian antar responden (Ascarya: 2012). Adapun rumus untuk mendapatkan nilai $\mathrm{W}$ adalah:

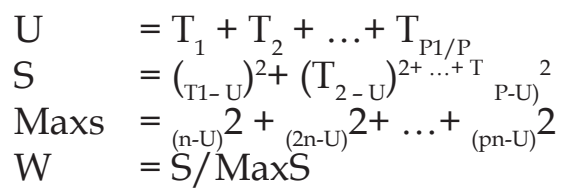

Keterangan

$\mathrm{U}$ : Nilai rata-rata dari total rangking

$S$ : Jumlah kuadrat deviasi

$\mathrm{P}$ : Jumlah node

$\mathrm{N}$ : Jumlah responden

$\mathrm{T}:$ Total

\section{Geometric Mean}

Ukuran ini digunakan untuk mengetahui penilaian individu dari para responden dan untuk mendapatkan pendapat pada suatu kelompok responden.Geometric Mean merupakan jenis perhitungan rata-rata yang menunjukkan kecenderungan atau nilai tertentu (Ascarya: 2012). Formulasinya adalah:

$$
\mathrm{GMk}=\left(\mathrm{R} 1 * \mathrm{R} 2^{*} \ldots \mathrm{n}\right) 1 / \mathrm{n}
$$

Keterangan:

GM : Geometrik Mean

$\mathrm{R} \quad$ : Responden

$\mathrm{N}$ : Jumlah responden

\section{HASIL DAN PEMBAHASAN}

\section{Gambaran Umum Fintech Asuransi}

Asuransi syariah merupakan suatu pengaturan pengelolaan risiko yang sesuai dengan ketentuan syariah, tolong menolong secara mutual yang melibatkan peserta dan perusahaan (Iqbal, 2006). Sebagaimana firman Allah SWT QS Al-Maidah ayat 2:

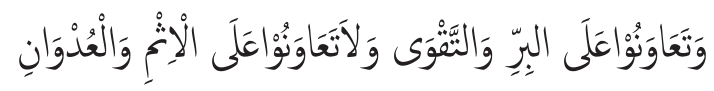

“..tolong-menolonglah kamu dalam (mengerjakan) kebaikan dan taqwa, dan janganlah kamu tolong-menolong dalam berbuat dosa dan pelanggaran". (QS Al-Maidah: 2)

\section{Hadist Nabi $S A W$}

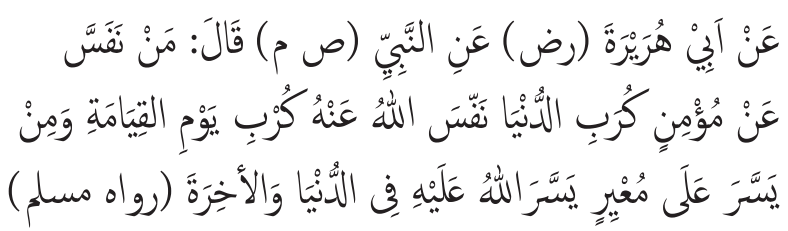

"Dari Abu Hurairah ra, Nabi Muhammad SAW bersabda: Barangsiapa yang menghilangkan kesulitan duniawinya seorang mukmin, maka Allah SWT akan menghilangkan kesulitannya pada hari Kiamat. Barangsiapa yang mempermudah kesulitan seseorang, maka Allah SWT akan mempermudah urusannya di dunia dan di akhirat". (HR Muslim)

\section{Financial Technology (Fintech)}

Financial Technology (fintech) syariah adalah bisnis berbasis teknologi dengan layanan keuangan inovatif atau produk yang menggunakan skema syariah. Fintech syariah mempromosikan keuangan yang bertanggungjawab, etis, dan memberikan peluang untuk memengaruhi semua bentuk keuangan secara global (Rusydiana, 2018).

Adapun fungsi fintech secara umum, yaitu transaksi keuangan daring, uang elektronik, akun virtual, aggregator, lembaga pinjaman, crowdfunding, dan perencanaan keuangan personal (Saksonova, 2017).

Peran fintech adalah sebagai berikut (Muchlis, 2018) :

1) Memberi solusi struktural bagi pertumbuhan berbasis elektronik (e-commerce)

2) Mendorong pertumbuhan usaha kecil dan menengah serta lahirnya wirausahawan (enterpreneur) baru.

3) Mendorong usaha kreatif (seperti artis, musisi, pengembang aplikasi, dsb) untuk meraih distribusi pasar yang luas (critical mass).

4) Memungkinkan pengembangan pasar, terutama masih yang belum terlayani jasa 
keuangan dan perbankan konvensional (unbanked population).

Tantangan fintech adalah sebagai berikut (Muchlis, 2018) :

1) Regulasi belum matang, aturan tumpang tindih, berpotensi menimbulkan penyelewengan.

2) Fintech membawa inovasi yang bersifat "merusak" (disruptive), berpotensi membuat air menjadi keruh.

3) Percepatan problem klasik teknologi: polarisasi pekerjaan akibat disintermediasi (job polarisation), melebarkan digital divide, dan pengkultusan sebagai jalan potong (shortcut) pertumbuhan ekonomi.

Program digitalisasi yang bijaksana dapat menghasilkan pengurangan biaya hingga $65 \%$, pengurangan waktu penyelesaian selama $90 \%$ pada proses asuransi utama, dan meningkatkan tingkat konversi hingga lebih dari 20\% (Catlin, Paliath, dkk, 2014).

Inovasi fintech pada Asuransi Syariah

Berdasarkan hasil literature review dan wawancara mendalam (indept interview) kepada para pakar dan praktisi fintech asuransi, inovasi fintech pada asuransi syariah terbagi kedalam tiga cluster yakni masalah, solusi dan strategi.

\section{Hasil Rater Agreement dan Geometric Mean Cluster Masalah}

Berdasarkan hasil pengolahan data pada permasalahan human dan produk, para responden memiliki perbedaan dalam menilai prioritas cluster masalah yang ditunjukkan melalui nilai kesepakatan (Rater Agreement) sebesar $(\mathrm{W}=1)$. Hasil Rater Agreement dengan nilai $W=1$, mengindikasikan bahwa tingkat kesepakatan responden dalam menilai masalah pada cluster tinggi (kesesuaian yang sempurna). Sehingga dapat disimpulkan bahwa terjadi kesepakatan antar responden dalam memberikan urutan peringkat guna mencari masalah utama berdasarkan rumusan cluster.

Pada cluster human, antar responden memiliki tingkat kesepakatan yang sangat rendah dalam meranking prioritas elemen yakni $(W=0.34)$. Enam orang responden sepakat bahwa masalah yang utama yang menjadi perhatian pada inovasi fintech pada asuransi syariah yakni kurangnya SDM tersebut dikarenakan pemerintah masih kurang memperhatikan dalam sumber daya manusia fintech asuransi syariah ini. Selain itu, satu responden lain menilai bahwasanya masalah utama pada cluster human yakni tantangan regulasi dikarenakan lamanya

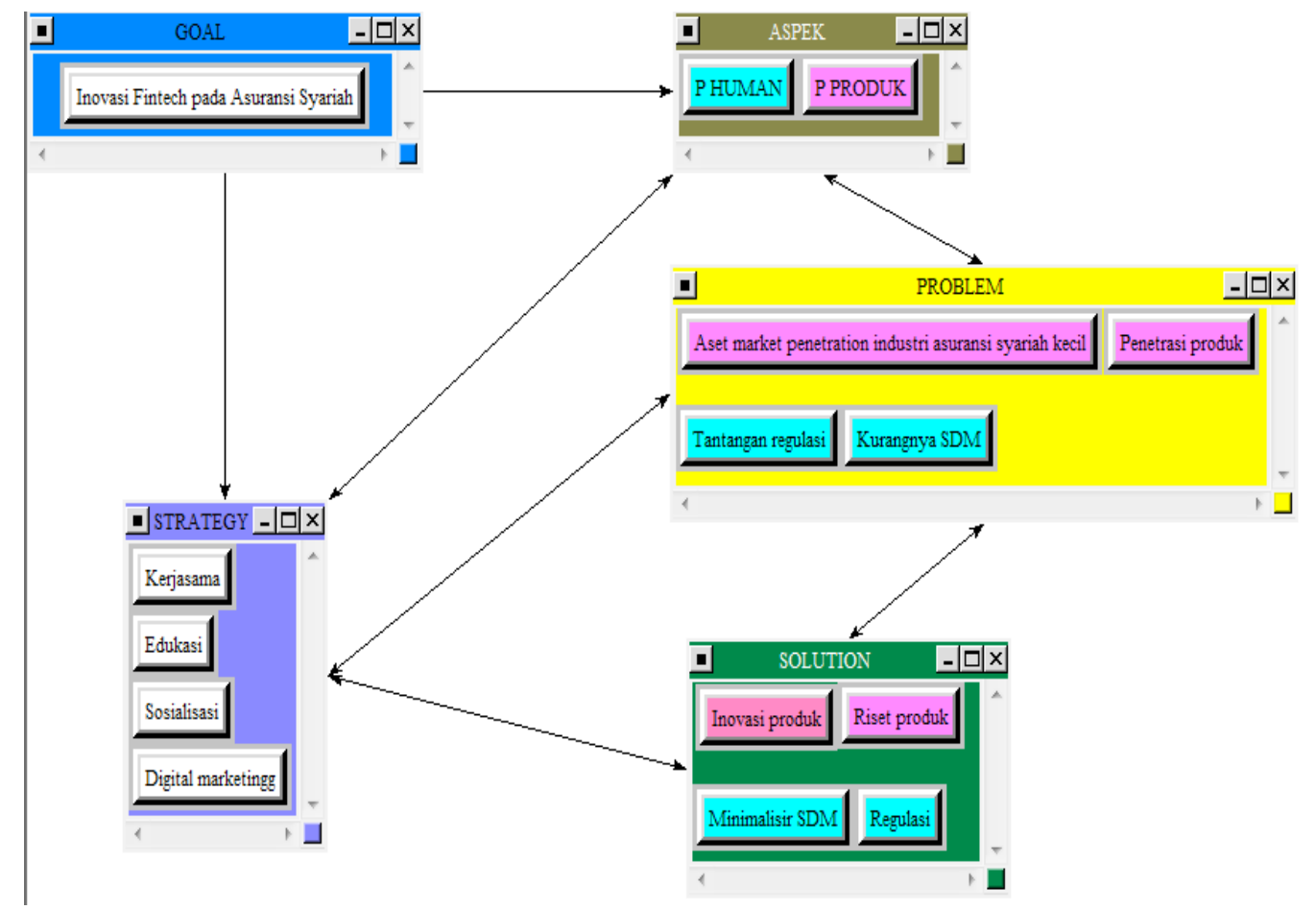

Gambar 1. Model Analytic Network Process Inovasi Fintech Asuransi 
proses perizinan ke OJK namun teknologi sudah semakin canggih.

Kemudian dilanjutkan dengan pengolahan data pada cluster produk. Ketujuh responden memiliki kesepakatan yang tinggi dalam menilai prioritas aspek masalah pada cluster produk yakni senilai $(\mathrm{W}=0.67)$. Jika melihat aspek pada cluster masalah produk, ketujuh responden memiliki pandangan yang berbeda-beda dalam menilai masalah yang menjadi prioritas utama. Namun mayoritas responden sepakat mengkategorikan Penetrasi produk sebagai prioritas pertama dari dua permasalahan yang ada.

Hasil keseleuruhan dari seluruh responden yang dilihat dari nilai Geometric Mean menunjukkan bahwa prioritas permasalahan pada aspek human yaitu kurangnya SDM, selanjutnya urutan kedua tantangan regulasi. Terkait permasalahan pada aspek produk fintech asuransi syariah yang menempati urutan prioritas, yaitu penetrasi produk dan kedua terletak pada Asset market penetration asuransi syariah kecil. Secara keseluruhan dari dua masalah utama pada fintech asuransi syariah yakni urutan pertama dari permasalahan human terkait kurangnya SDM dengan nilai 0.510. Urutan kedua dari permasalahan human terkait tantangan regulasi dengan nilai 0.239. Lalu diurutan ketiga dari permasalahan produk fintech asuransi syariah yakni penetrasi produk dengan nilai 0.161 .
Saksonova \& Merlino (2017) mengatakan bahwa aspek SDM menjadi salah satu prioritas utama dalam inovasi fintech asuransi. Rusydiana (2016) menjelaskan bahwa SDM menjadi masalah umum yang dihadapi industri keuangan syariah. SDM sangat diperlukan karena apabila SDM terpenuhi fintech mengalami perkembangan (Rusydiana, 2018).

\section{Hasil Rater Agreement dan Geometric Mean Cluster Solusi}

Berdasarkan hasil pengolahan data pada permasalahan human dan produk, para responden memiliki perbedaan dalam menilai prioritas cluster solusi yang ditunjukkan melalui nilai kesepakatan (Rater Agreement) sebesar $(\mathrm{W}=1)$. Hasil Rater Agreement dengan nilai $\mathrm{W}=$ 1, mengindikasikan bahwa tingkat kesepakatan responden dalam menilai masalah pada cluster tinggi (kesesuaian yang sempurna). Sehingga dapat disimpulkan bahwa terjadi kesepakatan antar responden dalam memberikan urutan peringkat guna mencari masalah utama berdasarkan rumusan cluster.

Pada cluster human, antar responden memiliki tingkat kesepakatan yang sangat rendah dalam meranking prioritas elemen yakni $(W=0.34)$. Enam orang responden sepakat bahwa masalah yang utama yang menjadi perhatian pada inovasi fintech pada asuransi syariah yakni Minimalisir SDM

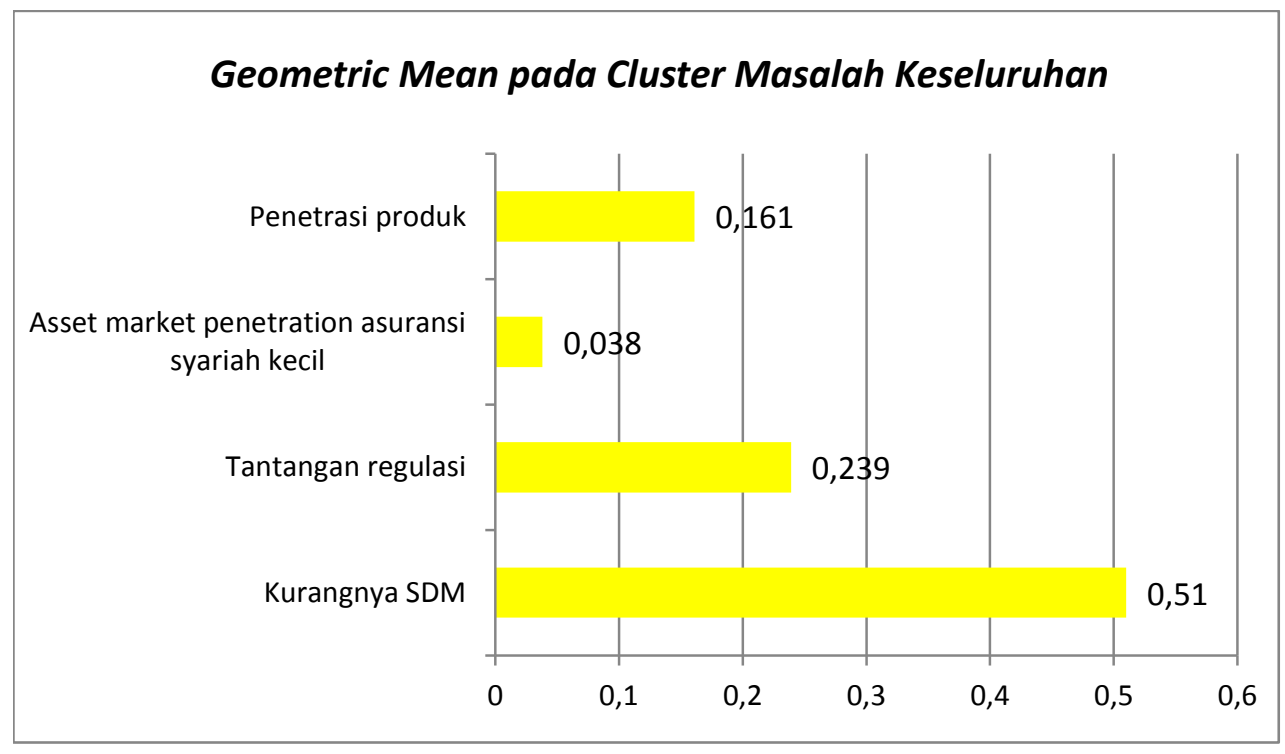

Gambar 2: Hasil Geometric Mean (GMk) Cluster Masalah 


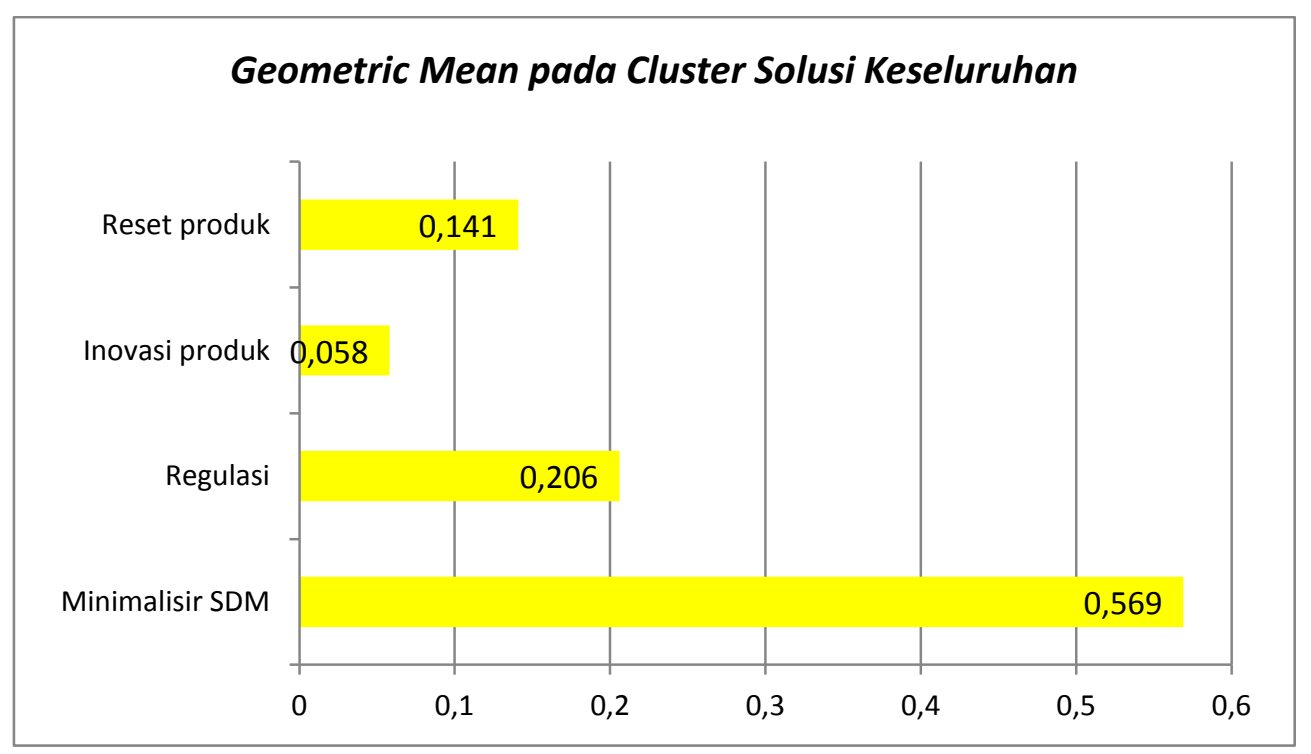

Gambar 3: Hasil Geometric Mean (GMk) Cluster Solusi

tersebut dikarenakan pemerintah masih kurang memperhatikan dalam sumber daya manusia terutama untuk fintech asuransi syariah ini. Selain itu, satu responden lain menilai bahwasanya masalah utama pada cluster human yakni regulasi dikarenakan lamanya proses perizinan ke OJK namun teknologi sudah semakin canggih.

Kemudian dilanjutkan dengan pengolahan data pada cluster produk. Ketujuh responden memiliki kesepakatan yang tinggi dalam menilai prioritas aspek masalah pada cluster produk yakni senilai $(\mathrm{W}=0.34)$. Jika melihat aspek pada cluster masalah produk, ketujuh responden memiliki pandangan yang berbeda-beda dalam menilai masalah yang menjadi prioritas utama. Namun mayoritas responden sepakat mengkategorikan Reset Produk sebagai prioritas pertama dari dua permasalahan yang ada.

Hasil keseleuruhan dari seluruh responden yang dilihat dari nilai Geometric Mean menunjukkan bahwa prioritas solusi pada aspek human yaitu minimalisir SDM, Selanjutnya urutan kedua regulasi. Terkait solusi pada aspek produk fintech asuransi syariah yang menempati urutan prioritas, yaitu reset produk dan kedua terletak pada inovasi produk. Secara keseluruhan dari dua masalah utama pada fintech asuransi syariah yakni urutan pertama dari solusi human terkait minimalisir SDM dengan nilai 0.569. Urutan kedua dari permasalahan human terkait regulasi dengan nilai 0.206. Lalu diurutan ketiga dari permasalahan produk fintech asuransi syariah yakni reset produk dengan nilai 0.141.

Hal ini bahwa elemen minimalisir SDM sangatlah penting sebagai salah satu penunjang untuk inovasi fintech terkhusus asuransi syariah. Intarto (2018) mengatakan bahwa Indonesia dengan sumber daya alam dan manusianya memiliki potensi menjadi negara dengan ekonomi yang maju. Dengan adanya revolusi industri 4.0 yang berbasis teknologi dan internet tentu memperbesar peluang Indonesia untuk memakmurkan rakyatnya. Adanya teknologi dan akses internet yang jauh lebih mudah, cepat dan murah bagi rakyat, tentu akan meningkatkan partisipasi Indonesia dalam ekonomi digital.

\section{Hasil Rater Agreement Cluster Strategi}

Berdasarkan dari pengolahan data hasil rater agreement pada cluster strategy mengahasilkan nilai Kendall's Coefficient of Concordance W sebesar 0.97 ini menunjukkan bahwa tingkat kesepakatan responden tinggi. Nilai Rater Agreement $\mathrm{W}=0.97$ mengindikasikan bahwa tingkat kesepakatan para responden dalam menilai cluster strategy masih tinggi.

Hasil keseleuruhan dari seluruh responden yang dilihat dari nilai Geometric Mean menunjukkan bahwa prioritas strategi fintech asuransi syariah adalah sosialisasi 


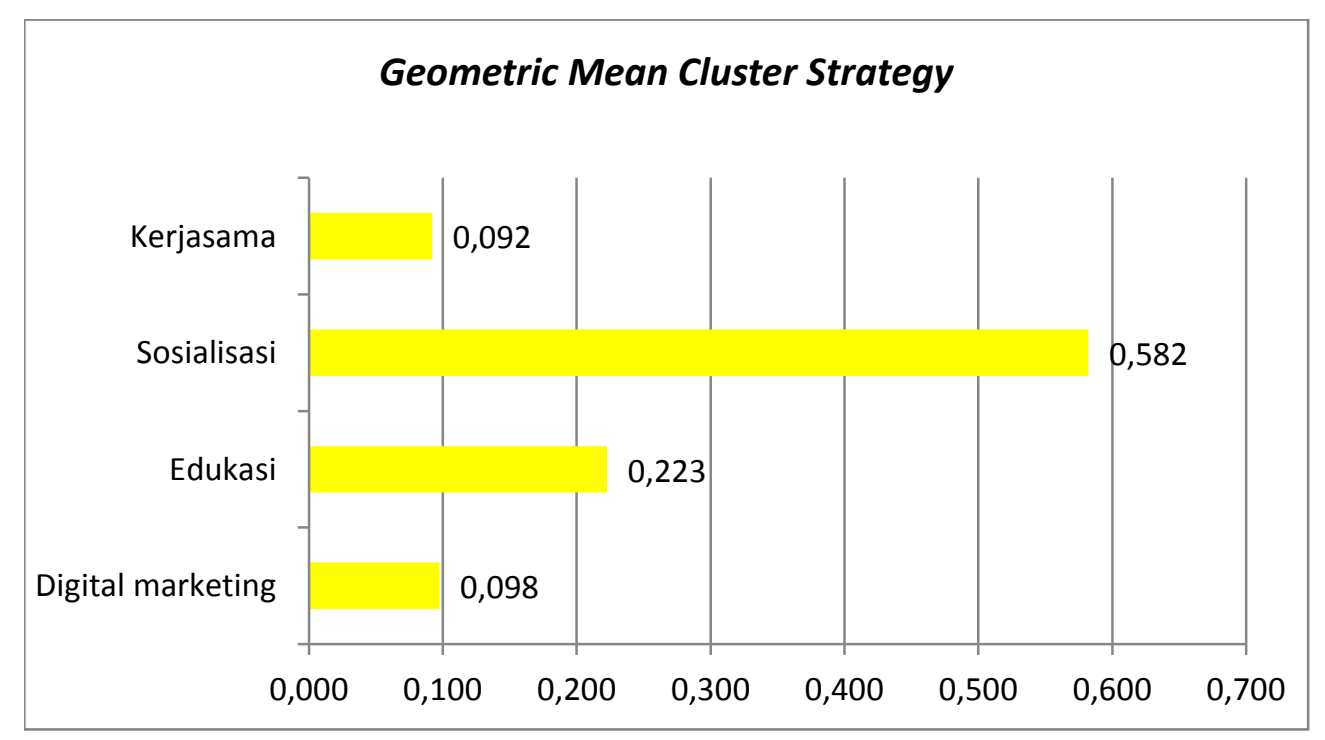

Gambar 4: Hasil Geometric Mean (GMk) pada Cluster Strategi

diurutan pertama dengan nilai 0.582. Lalu diurutan kedua yaitu edukasi dengan nilai 0.223. diurutan ketiga terkait kerjasama dengan nilai 0.098. Dan diurutan keempat terkait digital marketing dengan nilai 0.092 .

Hal ini menunjukkan bahwa sosialisasi harus dioptimalkan dengan mengajak masyarakat untuk memperkenalkan fintech dan pentingnya berasuransi. Mengingat pentingnya pengenalan teknologi dalam bidang layanan keuangan ini bagi masyarakat, khususnya yang jauh dari jangkauan perbankan dan lembaga keuangan dan meningkatkan kebutuhan layanan keuangan bagi masyarakat yang lebih fleksibel, mudah, cepat dan aman, maka perlu adanya sosialisasi,edukasi bagi masyarakat mengenai fintech (Suharyati \& Sofyan, 2018).

\section{KESIMPULAN}

Penelitian ini bertujuan untuk mengetahui masalah, solusi dan strategi pada inovasi fintech pada asuransi syariah. Berdasarkan hasil penelitian yang dilakukan dengan menggunakan Software Super Decisions Versi 2.0.8. Maka dapat disimpulkan bahwa:

Pertama, masalah inovasi fintech pada asuransi syariah pada akhirnya mengerucut pada dua masalah pokok, yakni aspek human dan aspek produk.

Kedua, aspek human meliputi (kurangnya sumber daya manusia dan tantangan regulasi), aspek produk meliputi (asset market penetration asuransi syariah kecil dan penetrasi produk).
Ketiga, solusi yang ditawarkan untuk permasalahan pada fintech asuransi syariah terbagi lagi menjadi dua aspek utama, yakni aspek human (minimalisir SDM dan regulasi), aspek produk (reset produk dan inovasi produk). Dari hasil pengolahan data, dihasilkan prioritas utama dari solusi adalah dari aspek human yakni minimalisir SDM. Diurutan kedua aspek human terkait regulasi. Dan diurutan yang ketiga terkait reset produk

Keempat, strategi dari hasil pengolahan data dihasilkan prioritas strategi dalam inovasi fintech asuransi sesuai dengan prioritas gabungan adalah pricing strategy, kerjasama, digital marketing dan sosialisasi.

\section{DAFTAR PUSTAKA}

Ascarya. (2005). Analytic Network Process (ANP): Pendekatan Baru Studi Kualitatif, Pusat Pendidikan dan Studi Kebanksentralan, Bank Indonesia.

Asuransi Digital Untuk Kaum Milenial. (2019, Jul 8). Dunia Fintech.

Catlin T., Paliath P,dkk. 2014, Insurance companies Untapped Digital Opportunity, "Harvard Business Review", March, https://hbr.org/2014/03/insurancecompanies-untapped-digital-opportunity (access: 09.12.2018)

Chrismastianto, I. (2017). Analisis SWOT Implementasi Teknologi Finansial Terhadap Kualitas Layanan Perbankan di Indonesia. Jurnal Ekonomi dan Bisnis, Volume 20 (1). 
Intarto, E. A. (2018). Fintech dan Cashless Society: Sebuah Revolusi Pendongkrak Ekonomi Kerakyatan. Essay Booklet; The Transformative Power of Fintech.

Irfan, A. (2018). Dirut Bjb: Perbankan dan Fintech Bisa Bersinergi. Diakses pada 8 Juli 2019 dari https: / / bisnis.tempo.co

Iqbal, M. (2006). Asuransi Syariah dalam Praktik. Jakarta: Gema Insani Perss.

Leliya, M.K. (2012). Minat Masyarakt Berasuransi Syariah di Asuransi Prudential.

Napitupulu, Rubini Aldi Firmansyah, dkk. (2017). Kajian Perlindungan Konsumen Sektor Jasa Keuangan: Perlindungan Konsumen Pada Fintech Jakarta : Departemen Perlindungan Konsumen OJK.

Muchlis, R. (2018). Analisis SWOT Financial Technology (Fintech) Pembiayaan Perbankan Syariah Di Indonesia (Studi Kasus 4 Bank Syariah Di Kota Medan). At-Tawassuth,Volume III (2)
Rusydiana, A.S. (2018). Bagaimana Mengambangkan Industri Fintech Syariah di Indonesia? Pendekatan Interpretive Structural Model (ISM). Jurnal Al-Muzra'ah Volume 6 (2)

Saaty, T.L., \& L.G Vargas. (2006). Decision Making with the Analytic Network Process: Economic, Political, Social and Technological Applications with Benefit, Opportunities, cost and Risks. $2^{\text {nd }}$ Edition. Springer Science+ Business Media. New York

Sari,A.R. (2015). Faktor-faktor Yang Mempengaruhi Kurangnya Minat Masyarakat Muslim di Bank Syariah (Studi Kasus Masyarakat Muslim di Kabupaten Bantul Yogyakarta).

Tanjung, H \& Devi,A. (2013). Metodologi Penelitian Islam. Jakarta: Gramata Publishing.

Yusandani, A.M. (2018). Analisis Yuridis Perjanjian Asuransi Digital (Studi Pada PT FWD Life Indonesia). Skripsi. Universitas Lampung. 